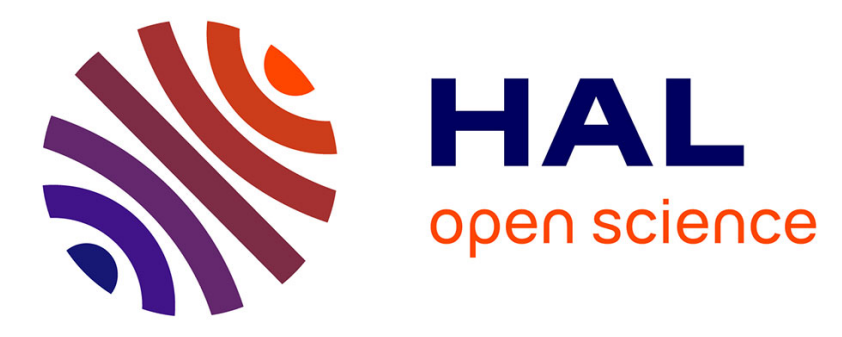

\title{
Online analysis of gas-phase radical reactions using vacuum ultraviolet lamp photoionization and time-of-flight mass spectrometry
}

Zuoying Wen, Xiaofeng Tang, Christa Fittschen, Cuihong Zhang, Tao Wang, Chengcheng Wang, Xuejun Gu, Weijun Zhang

\section{To cite this version:}

Zuoying Wen, Xiaofeng Tang, Christa Fittschen, Cuihong Zhang, Tao Wang, et al.. Online analysis of gas-phase radical reactions using vacuum ultraviolet lamp photoionization and time-of-flight mass spectrometry. Review of Scientific Instruments, 2020, Review of Scientific Instruments, 91 (4), pp.043201. 10.1063/1.5135387 . hal-02960839

\section{HAL Id: hal-02960839 \\ https://hal.univ-lille.fr/hal-02960839}

Submitted on 8 Oct 2020

HAL is a multi-disciplinary open access archive for the deposit and dissemination of scientific research documents, whether they are published or not. The documents may come from teaching and research institutions in France or abroad, or from public or private research centers.
L'archive ouverte pluridisciplinaire HAL, est destinée au dépôt et à la diffusion de documents scientifiques de niveau recherche, publiés ou non, émanant des établissements d'enseignement et de recherche français ou étrangers, des laboratoires publics ou privés. 


\title{
Online analysis of gas-phase radical reactions using vacuum ultraviolet lamp photoionization and time-of-flight mass spectrometry
}

\author{
Zuoying Wen, ${ }^{1,2}$ Xiaofeng Tang, ${ }^{1, a)}$ Christa Fittschen, ${ }^{3}$ Cuihong Zhang, ${ }^{1,2}$ Tao Wang, ${ }^{1}$ Chengcheng \\ Wang, ${ }^{1,2}$ Xuejun Gu, ${ }^{1}$ and Weijun Zhang ${ }^{1,4, a)}$ \\ ${ }^{1}$ Laboratory of Atmospheric Physico-Chemistry, Anhui Institute of Optics and Fine Mechanics, \\ Chinese Academy of Sciences, Hefei, 230031 Anhui, China \\ ${ }^{2}$ Graduate School, University of Science and Technology of China, Hefei, 230026 Anhui, China \\ ${ }^{3}$ University Lille, CNRS, UMR 8522, PC2A - Physicochimie des Processus de Combustion et de \\ l'Atmosphère, F-59000 Lilld, France \\ ${ }^{4}$ School of Environmental Science and Optoelectronic Technology, University of Science and \\ Technology of China, Hefei, 230026 Anhui, China
}

A home-made vacuum ultraviolet (VUV) photoionization time-of-flight mass spectrometer has been developed and coupled to an atmospheric simulation chamber operated at atmospheric pressure and to a fast flow tube at low pressure (1-10 Torr). Gas sampling from the chamber is realized directly via a capillary effusive beam, and sampling from the flow tube is via a continuous molecular beam inlet. Both devices are connected simultaneously to the ionization chamber and can be switched in-between within minutes to study gas-phase radical reactions of atmospheric interest in a large range of reaction conditions and reaction times (from milliseconds in the flow tube to hours in the simulation chamber). A cage-shaped photoionization source combined with a commercial $10.6 \mathrm{eV}$ krypton lamp has been developed to provide a high ion collection efficiency along the long light path in the cage. This way, a multiplexed detection with high sensitivity down to the sub-ppbv concentration range, e.g. a limit of detection (LOD) of $0.3 \mathrm{ppbv}$ for benzene and $1.3 \mathrm{ppbv}$ for the methyl radical, is obtained. The performance and suitability of the setup is illustrated by the study of the chlorine-initiated oxidation reaction of toluene in the atmospheric simulation chamber and in the fast flow tube. Stable products and reactive intermediates have been well determined and their reaction dynamics are discussed.

a) Authors to whom correspondence should be addressed: tangxf@aiofm.ac.cn and wjzhang@aiofm.ac.cn 


\section{INTRODUCTION}

Mass spectrometry as a versatile and sensitive analysis tool has the power to provide qualitative and quantitative information and has already been successfully applied in a wide range of fields. In comparison to hard ionization techniques, soft ionization techniques such as matrix-assisted laser desorption ionization (MALDI), electrospray ionization (ESI), chemical ionization (CI) and photoionization can produce high molecular ion yields with minimal fragmentation and have had a large influence on the development of mass spectrometry. ${ }^{1,2}$ Among them, single-photon ionization with vacuum ultraviolet (VUV) radiations has the ability to ionize compounds including both polar and nonpolar species without matrix effects and has the potential to be a universal soft ionization method. The coupling of VUV photoionization with mass spectrometry has attracted a great deal of attention and provided valuable data at an unprecedented level of detail. ${ }^{3-5}$

VUV photoionization mass spectrometry has made considerable progresses benefiting from the improvement of light sources including VUV lamps, lasers and synchrotron radiation. Synchrotron radiation has the merit of high photon flux, wide energy range and easy tunability, and is considered as an ideal single-photon ionization source. The description of VUV photoionization endstations at synchrotron facilities and their diverse applications can be found in the literature. ${ }^{6-9}$ But the problem of synchrotron facilities is that it cannot be moved outside for field experiments and that the available beamtime for each user is very limited. For VUV lasers, frequency tripling of the third harmonic emitted from a Nd:YAG laser at $355 \mathrm{~nm}$ and four-wave mixing of UV pulses in a rare gas cell are often utilized to generate VUV photons. ${ }^{10-12}$ But lasers are difficult to tune in the VUV range and the setups are sensitive to the fluctuation of laser pulse energy. ${ }^{3}$

The combination of VUV lamp photoionization and mass spectrometer for use in kinetics was first developed by Bayes et al., and further developed by Gutman and Fockenberg et al. ${ }^{13-15}$ But, unlike synchrotron radiation and lasers, VUV lamps usually have a low photon flux with a narrow spectral range. However, besides the low price, VUV lamps have the advantage of being robust with a small volume and of being almost 
maintenance free, well suited for mass spectrometer with a compact design and mobile experiments. In particular with an appropriate design of the ionization source, the disadvantage of VUV lamps, e.g. the low photon flux, can be compensated and then a detection with a high sensitivity has been approached. The limits of detection (LODs) of some typical VUV-lamp photoionization time-of-flight (TOF) mass spectrometers with different lamps and pressures inside the ionization source are listed in Table 1, and are found to be even better than those using lasers or synchrotron radiations. ${ }^{7,8,16,17}$

The configuration of the ionization source is important for the detection sensitivity and the recent improvements were mainly benefiting from the pressure increase inside the ionization source. For example, after increasing the ionization source pressure up to 700 Pa, Wang et al obtained a LOD of 15 pptv (parts per trillion by volume) for aliphatic and aromatic hydrocarbons. ${ }^{19}$ Employing a RF-powered VUV lamp with a photon flux $\sim 2 \times$ $10^{14}$ photons $\mathrm{s}^{-1}$ and increasing the pressure inside the ionization source up to $1300 \mathrm{~Pa}$, Shu et al. achieved LODs 0.30-0.69 pptv for volatile aldehydes. ${ }^{21}$ But the ionization mechanism of Shu's setup is complex: photoionization induces other ionization mechanisms, leading to adduct formation such as acetone and acetic acid.

Table 1. Limits of detection (LODs) of typical time-of-flight mass spectrometers with different photoionization light sources and pressures $\left(\mathrm{P}_{\text {ion }}\right)$ inside the ionization source.

\begin{tabular}{llllll}
\hline Light sources & $\lambda(\mathrm{nm})$ & $P_{\text {ion. }}(\mathrm{Pa})$ & $\begin{array}{l}\text { Photon } \\
\left(\text { photon }^{-1}\right)\end{array}$ & $\begin{array}{l}\text { LODs }^{\mathrm{a}} \text { (ppbv) } \\
\text { /Accumulated } \\
\text { time }\end{array}$ & Refs. \\
\hline ALS & 122 & $\sim 10^{-2}$ & $5 \times 10^{13}$ & $20 / 60 \mathrm{~s}^{\mathrm{b}}$ & 7 \\
NSRL & 89 & $\sim 10^{-2}$ & $\sim 10^{13}$ & $<100 / 5 \mathrm{~s}^{\mathrm{c}}$ & 8 \\
Laser & 118 & $\sim 10^{-3}$ & $2 \times 10^{11}$ & $8 / 5 \mathrm{~s}$ & 16 \\
Laser & 118 & $\sim 10^{-3}$ & --- & $3 /$ & 17 \\
EBEL & 126 & $\sim 10^{-3}$ & $1 \times 10^{14}$ & $27 / 1 \mathrm{~s}$ & 20 \\
Kr lamp & 117 & 30 & $\sim 10^{11}$ & $3 / 10 \mathrm{~s}$ & 18 \\
Kr lamp & 117 & 700 & $\sim 10^{11}$ & $0.015 / 60 \mathrm{~s}$ & 19 \\
RF Kr lamp & 124 & 1000 & $5 \times 10^{14}$ & $0.003 / 10 \mathrm{~s}$ & 21 \\
Kr lamp & 117 & $10^{-2}$ & $\sim 10^{11}$ & $0.3(1.3) / 60 \mathrm{~s}^{\mathrm{d}}$ & $\begin{array}{l}\text { This } \\
\text { work }\end{array}$ \\
\hline
\end{tabular}

${ }^{\mathrm{a}}$ Most of LODs for benzene, ${ }^{\mathrm{b}}$ for acetone, ${ }^{\mathrm{c}}$ for $\mathrm{CO}_{2},{ }^{\mathrm{d}} 0.3 \mathrm{ppbv}$ for benzene and $1.3 \mathrm{ppbv}$ for the methyl radical. ALS: Advanced Light Source, US; NSRL: National Synchrotron Radiation Laboratory, China; 
EBEL: Electron beam pumped excimer lamp.

VUV-lamp photoionization mass spectrometers have been mainly applied on the detection of stable species like volatile organic compounds (VOCs), and seldom on reactive intermediates. Also up to now we only find very few reports on the LOD of reactive intermediates like radicals with VUV photoionization mass spectrometry in the literature. ${ }^{7,17}$ One possible reason is that the available photoionization cross sections of radicals are very scarce ${ }^{22-25}$ and so it is difficult to quantify them with photoionization mass spectrometry, especially for VUV lamps often with multiple output photon energies. Another reason may be that within the above mentioned high pressure environment the concentration of reactive radicals rapidly declines during transfer into the ionization source.

In this manuscript, we present a VUV-lamp photoionization orthogonal acceleration reflectron time-of-flight mass spectrometer (VUVPI-TOFMS) for online analysis of radical reactions of atmospheric interest. A novel cage-shaped photoionization source combined with a commercial $10.6 \mathrm{eV}$ krypton lamp has been developed. A focusing electric field ${ }^{26}$ is then formed to allow all the ions produced along the long light path of the krypton lamp to be extracted, making the achieved LODs of the VUVPI-TOFMS comparable to the above setups with medium pressure ionization source in Table 1. Here, the pressure inside the cage-shaped photoionization source is low at $\sim 10^{-2} \mathrm{~Pa}$, and both stable species and reactive intermediates can thus be transferred into the photoionization region to be ionized and analyzed.

In addition, two reactors, an atmospheric simulation chamber operated at atmospheric pressure and a fast flow tube at low pressure (1-10 Torr), are coupled simultaneously to the ionization chamber of the VUVPI-TOFMS in order to initiate radical reactions at different pressures and to study the time-resolved evolution of the gas mixture over different reaction times, in the minutes to hours range in the atmospheric simulation chamber and in the millisecond range in the fast flow tube. As far as we known, this is the first setup which allows the simultaneous connection of both, an atmospheric simulation chamber and a fast flow tube, independently to the same mass spectrometer in order to investigate atmosphere radical reactions at different pressures 
and reaction times, switching from one reactor to the other is possible within minutes. A multiplexed detection with a high sensitivity down to sub-ppbv concentration range has been obtained. As representative examples, the chlorine-initiated oxidation reaction of toluene has been studied in the atmospheric simulation chamber at atmospheric pressure and in the fast flow tube at 2 Torr, and preliminary results are also discussed.

\section{EXPERIMENTAL}

A schematic diagram of the setup is shown in Fig. 1. The atmospheric simulation chamber and the fast flow tube are employed as chemical reactors to initiate radical reactions at different pressures and follow them over different reaction times. The atmospheric simulation chamber is connected to the VUVPI-TOFMS via a capillary while the fast flow tube is connected via a continuous molecular beam. The home-made compact VUVPI-TOFMS is composed of three chambers, the source, the ionization and the TOF chambers, and mainly consists of three parts, sampling inlets, a VUV lampbased photoionization source and an orthogonal accelaration reflectron TOF mass analyzer.

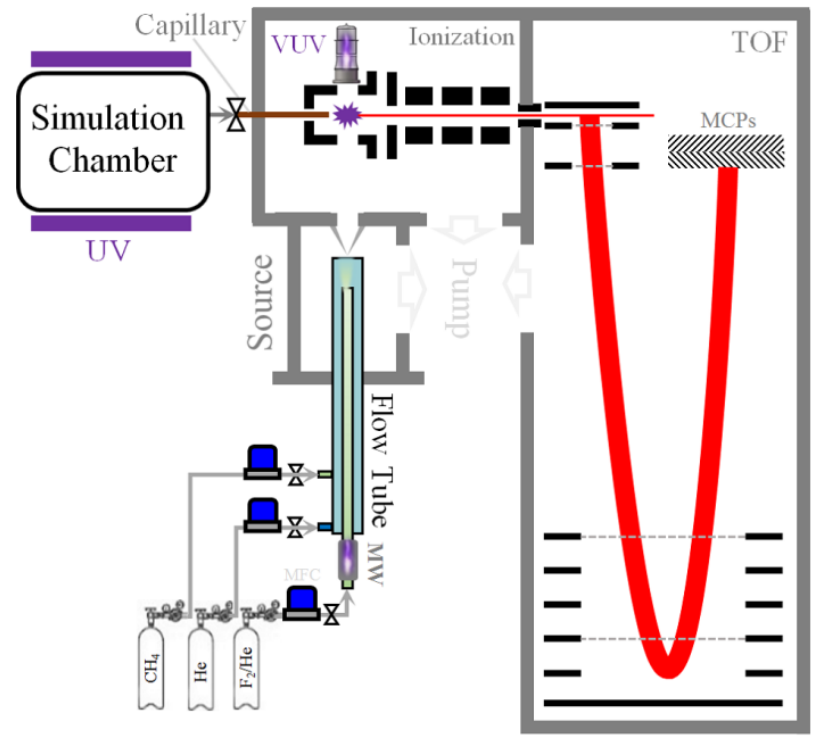

FIG. 1. Schematic diagram of the VUV-lamp photoionization orthogonal acceleration reflectron time-of-flight mass spectrometer with a capillary effusive beam and a continuous molecular beam connected to an atmospheric simulation chamber and a microwave discharge (MW) flow tube to investigate radical reactions at different pressures and reaction times.

\section{A. Chemical reactors}


The configuration of the atmospheric simulation chamber has been introduced in our previous publications and is mainly made of a $150 \mathrm{~L}$ Teflon bag surrounded by several UV lamps emitting photons with wavelength at around $254 \mathrm{~nm} .{ }^{27,}{ }^{28}$ Clean air from a pure air generator (AADCO 737-series) was used as bath gas in the Teflon bag. The Teflon bag was operated at atmospheric pressure and presently was connected to the VUVPITOFMS directly via a fused silica capillary (Part 160-1010, Agilent Technologies, US) with a length of $20 \mathrm{~cm}$ and $0.1 \mathrm{~mm}$ inner diameter. As shown in Fig. 1, the capillary acted as an atmospheric pressure inlet and its tip penetrated directly into the photoionization region. The pressure of the ionization chamber increased from $10^{-5}$ to $10^{-2} \mathrm{~Pa}$ with the capillary sampling on and then an effusive beam was formed. Stable species could be transferred from the Teflon bag to the photoionization source of the VUVPI-TOFMS through the capillary.

The fast flow tube is similar to the previous design ${ }^{29,30}$ and was composed of a 45 cm long Pyrex main tube with 20/16 mm outer/inner diameter, and a $50 \mathrm{~cm}$ long coaxial movable injector with $6 / 4 \mathrm{~mm}$ outer/inner diameter. Fluorine or chlorine atoms utilized as radical initiators were generated from diluted $\mathrm{F}_{2}$ or $\mathrm{Cl}_{2}$ gas in helium by a $2.45 \mathrm{GHz}$ microwave discharge generator (GMS-200W, Sairem, France). Other reactant and bath gases were fed into the flow tube via the injector or the side arms of the main tube. The gases were measured with individual calibrated mass flow controllers (MFC, D07-7B, Sevenstars, China). The pressure inside the flow tube was maintained at 1-10 Torr by a closed-loop feedback throttle valve (61532-KEGG, VAT) installed between the source chamber and a $10 \mathrm{~L} \mathrm{~s}^{-1}$ scroll pump (XDS35i, Edwards). At the downstream of the flow tube, a $1 \mathrm{~mm}$ diameter quartz skimmer was installed on the wall between the source and the ionization chambers and a continuous molecular beam was formed, where both stable species and reactive intermediates in the flow tube were sampled and transferred into the photoionization region. The distance between the tip of the injector and the skimmer can be adjusted and thus the reaction time can be changed.

The atmospheric simulation chamber and the fast flow tube were operated independently and the sampling from one or the other reactor could be exchanged in minutes, just manually opening or closing the valves on their individual gas circuits shown in Fig. 1. The distinctive characteristics of the atmospheric simulation chamber is 
that it can be used for studying radical reactions at atmospheric pressure by following the concentration of stable species over reaction times from minutes to several hours, in contrary to the fast flow tube where the reaction time is much shorter (several $10 \mathrm{msec}$ ) but reactive intermediates like radicals can be detected through the molecular beam sampling.

\section{B. Cage-shaped photoionization source}

The species sampling from the capillary effusive beam or the continuous molecular beam cross the VUV light at a right angle in the photoionization region and species having an ionization energy below the VUV photon energy can be ionized. A commercial krypton lamp (PKS106, Heraeus, Germany) with two atomic resonant lines at $\mathrm{h} v=10.0$ and $10.6 \mathrm{eV}$ was employed as the VUV light source. The krypton lamp was sealed with a $\mathrm{MgF}_{2}$ window and its light entered into the photoionization region directly without focusing. The VUV light beam of the krypton lamp has a larger size than those of lasers and synchrotron radiations and its photon flux is $\sim 1 \times 10^{11}$ photons $\mathrm{s}^{-1}$. Presently to utilize the photon flux as complete as possible and thus to promote the photoionization efficiency, the krypton lamp was installed directly inside the ionization chamber, right above the photoionization region within the vacuum.

In addition, in contrary to our previous design, ${ }^{30}$ a cage-shaped photoionization source with a cage electrode and a plate electrode has been developed to enhance the detection sensitivity, as shown in Fig. 2(a). The cage electrode has an inner diameter of $18 \mathrm{~mm}$ with four well-distributed holes ( $6 \mathrm{~mm}$ diameter) on the circle and one hole on the head to let the VUV light and gas in and out. The working pressure inside the

photoionization region was low at about $10^{-2} \mathrm{~Pa}$ and the molecular mean free path is calculated to be $\sim 100 \mathrm{~cm}$, much larger than the dimensions of the photoionization region, allowing both stable species and reactive radicals to be transferred and to survive in the photoionization region. The plate electrode with a $6 \mathrm{~mm}$ inner diameter was located coaxially on the right of the cage electrode and was insulated with polyether-ether-ketone (PEEK) columns. 

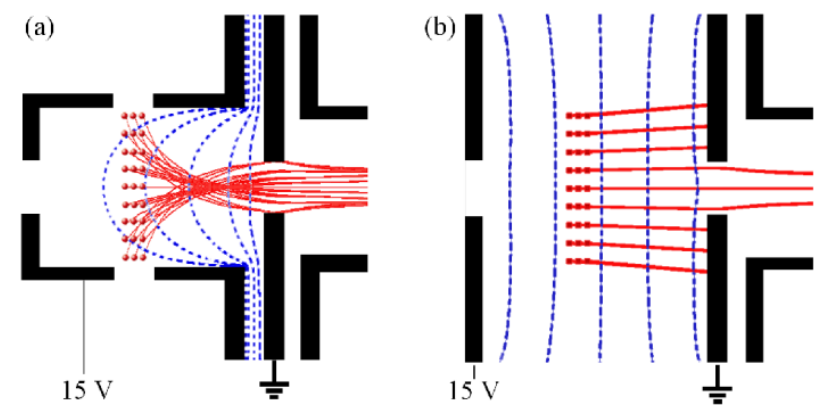

FIG. 2. (a) Geometry of the cage-shaped photoionization source and simulated ion trajectories (red solid lines) along the long light path of VUV lamp. The equi-potential curves (blue dotted lines) show the ion focusing effect of electric field in the cage. (b) The ion trajectories and the equi-potential curves of a parallel repelling ionization source.

\section{Orthogonal acceleration reflectron TOF mass analyzer}

A home-made orthogonal acceleration reflectron TOF mass analyzer ${ }^{30}$ was employed to analyze ion masses and its detailed configuration of electrodes is presented in Fig. 3. At the downstream of the cage-shaped photoionization source, an Einzel lens with three cylindrical tubes was installed to focus and transmit ions. Then after passing through a $2 \times 6 \mathrm{~mm}^{2}$ slit connecting the ionization and the TOF chambers, the ion beam with a transverse kinetic energy of $\sim 15 \mathrm{eV}$ was pushed and accelerated vertically by dual pulses of $\pm 600 \mathrm{~V}$ applied on the first and the third electrode of the extraction region of the reflectron TOF mass analyzer. The voltage of the second electrode of the extraction region was fixed at ground, see Fig. 3(c). The dual pulses can decrease the penetration of the direct electric field of the acceleration region and with this reduce the background signal.

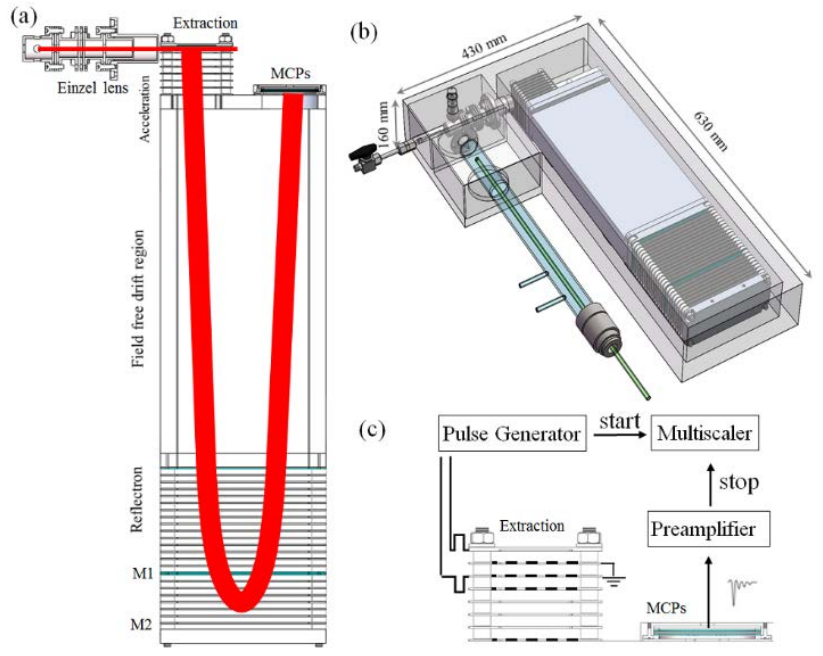


FIG. 3. (a) The detailed configuration of the VUVPI-TOFMS, mainly consisting of the cageshaped photoionization source, an Einzel lenses and an orthogonal acceleration reflectron TOF mass analyzer with ion trajectories in red. (b) The 3D layout of the setup with the VUV lamp, the capillary effusive beam inlet and the fast flow tube. (c) The dual pulses and ion signal process of the VUVPI-TOFMS.

After being accelerated with $2400 \mathrm{eV}$ kinetic energy within the acceleration region of the reflectron TOF mass analyzer, the ions flied into the field free drift region, entered the reflectron region with a double space-focusing configuration and then backed again into the field free drift region. Finally, the ions were detected by a pair of micro-channel plates (MCPs, $50 \mathrm{~mm}$ diameter) with a chevron configuration. The MCPs signals were amplified by a preamplifier and recorded by a multiscaler counter (TA2000B-1 \& P78882, FAST ComTec, Germany). As shown in Fig. 3(b), the VUVPI-TOFMS has a compact design with a length/width of 0.6/0.4 m and its typical parameters are listed in Table 2.

Table 2. Typical parameters of the VUV-lamp photoionization orthogonal acceleration time-offlight mass spectrometer.

\begin{tabular}{ll}
\hline Components & Key parameters \\
\hline Ionization source & Cage shape with $18 \mathrm{~mm}$ diameter; +15 V \\
Einzel lens & $0 \mathrm{~V},-30 \mathrm{~V}, 0 \mathrm{~V}$ \\
Slit & $2 \times 6 \mathrm{~mm}^{2}, 0 \mathrm{~V}$ \\
Extraction region & $12 \mathrm{~mm}$ length; $\pm 600 \mathrm{~V}$ pulse voltage, \\
& $35 \mathrm{kHz}, 1 \mu \mathrm{s}$ width \\
Acceleration region & $30 \mathrm{~mm}$ length; $-2400 \mathrm{~V}$ \\
Electric field-free drift region & $320 \mathrm{~mm}$ length; $-2400 \mathrm{~V}$ \\
Dual-stage ion reflector & $-195 \mathrm{~V}$ for mirror 1, \\
& $+795 \mathrm{~V}$ for mirror 2 \\
MCPs detector & $900 \mathrm{~V}$ per piece of MCP \\
\hline
\end{tabular}

\section{RESULTS AND DISCUSSION}

\section{A. Focusing effect of the cage-shaped photoionization source}

In this section, we focus on the focusing effect of the cage-shaped photoionization source and its performance. The electric field and the ion trajectories inside the cageshaped photoionization source were simulated and are presented as blue dotted lines and red solid lines in Fig. 2(a). The voltages of the cage electrode and the plate electrode were 
optimized and set at 15 and $0 \mathrm{~V}$, respectively. This way, a focusing electric field ${ }^{26}$ was formed and all the ions produced along the long light path of the VUV lamp could be extracted and passed through the hole of the plate electrode to be analyzed and detected.

To compare the ion focusing effect of the cage-shaped photoionization source, the electric field and the ion trajectories inside the traditional ionization source with two parallel plate electrodes ${ }^{8,30}$ were also simulated and are shown in Fig. 2(b). In this case a near parallel electric field was formed between the two plate electrodes and only the small fraction of the ions within the large volume, located at the center of the photoionization region, was extracted through the second plate electrode to be detected.

The ion collection efficiencies of the focusing electric field (Fig. 2a, the cage-shaped photoionization source) and the parallel electric field (Fig. 2b) are calculated and listed in Table 3. In the ionization chamber the ions can be produced along the long light path of the krypton lamp and so the photoionization region should take a shape of a cigar. In the calculation the length of the photoionization region is fixed at $18 \mathrm{~mm}$, i.e. the inner diameter of the cage electrode, whereas its diameter is varied from 1 to $3 \mathrm{~mm}$, as the exact diameter of the VUV light is not known. The calculated results show that the ion collection efficiency is slightly dependent on the volume of the ionization region, whereas the ratio of the ion collection efficiencies of the focusing electric field ( $\left.\mathrm{E}_{\text {cage }}\right)$ to the parallel electric field ( $E_{\text {para }}$ ) is almost independent. The ion collection efficiency of the focusing electric field is about three times higher than that of the parallel electric field, corresponding to the ratio of the inner diameter of the cage electrode to the one of the plate electrode.

Table 3. Calculated ion collection efficiencies of the focusing electric field ( $\left.E_{\text {cage }}\right)$ and the parallel electric field ( $\left.E_{\text {para }}\right)$ in Fig. 2.

\begin{tabular}{cccc}
\hline Ionization region $(\mathrm{mm})$ & $\mathrm{E}_{\text {cage }}$ & $\mathrm{E}_{\text {para }}$ & $\mathrm{E}_{\text {cage }} / \mathrm{E}_{\text {para }}$ \\
\hline$\varnothing 1 \times 18$ & 0.84 & 0.32 & 2.7 \\
$\varnothing 2 \times 18$ & 0.79 & 0.29 & 2.7 \\
$\varnothing 3 \times 18$ & 0.73 & 0.26 & 2.8 \\
\hline
\end{tabular}


In addition, to experimentally demonstrate the focusing effect of the cage-shaped photoionization source, we have also performed VUV lamp photoionization experiments with the above two kinds of photoionization sources, the cage-shaped photoionization source and the parallel photoionization source, by using the capillary effusive beam inlet and the VUVPI-TOFMS. The photoionization mass spectra of a gas mixture of benzene, toluene and p-xylene were measured with the two photoionization sources respectively, whereas the other experimental conditions were the same, and are presented in Fig. 4. In the mass spectra, the intense peaks at $\mathrm{m} / \mathrm{z}=78,92$ and 106 are assigned as the ions of benzene, toluene and p-xylene, and the accompanied $\mathrm{m} / \mathrm{z}=79$, 93 and 107 peaks can be assigned as their individual ${ }^{13} \mathrm{C}$ isotopic species. The ionization energies of benzene, toluene and p-xylene locate at 9.244, 8.828 and $8.445 \mathrm{eV}$, respectively, close to the photon energies of the krypton lamp. ${ }^{31}$ Benzene, toluene and p-xylene had been softly ionized with the VUV photons and no fragment ions were observed in the mass spectra. From the width of the ion peak of benzene, the mass resolution of the VUVPI-TOFMS is measured to be $\mathrm{M} / \mathrm{M} \sim 1500$ (FWHM, the full width at half maximum). In addition, the ion intensities of benzene, toluene and p-xylene in the mass spectrum obtained with the cage-shaped photoionization source have been increased for 2.6, 2.3 and 2.1 times, respectively, compared to those with the parallel photoionization source, agreeing well with the above simulated results.

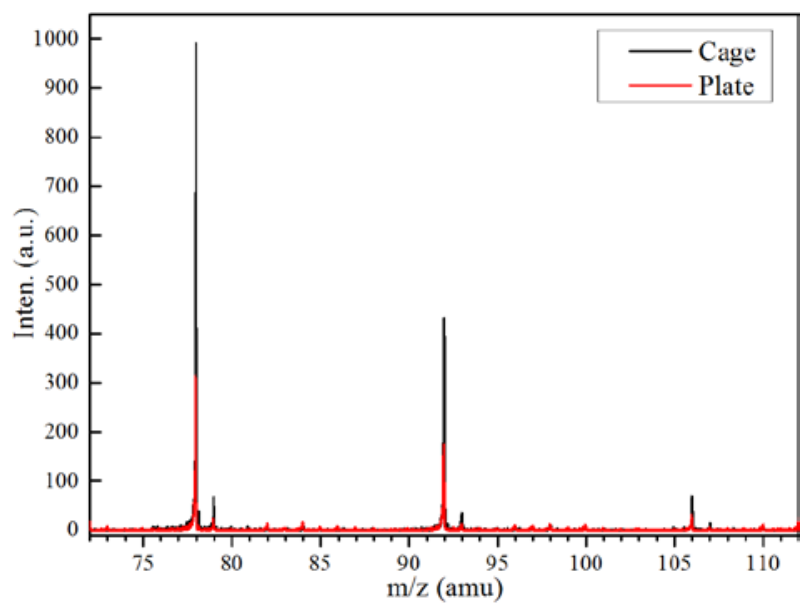

FIG. 4. VUV lamp photoionization mass spectra of benzene, toluene and p-xylene, measured with the cage-shaped photoionization source (in black) and the parallel photoionization source (in red) of Fig. 2.

\section{B. LODs of stable species}


A gas mixture of benzene, toluene and p-xylene with calibrated concentrations of 10 ppmv (Nanjing Special Gases Co. Ltd., China) was used to characterize the detection sensitivity of the VUVPI-TOFMS. The calibrated gas was dynamically diluted with helium through mass flow controllers and their photoionization mass spectra were measured by sampling through the capillary effusive beam. As shown in Fig. 5(a), the ion intensities of benzene $(\mathrm{m} / \mathrm{z}=78)$, toluene $(\mathrm{m} / \mathrm{z}=92)$ and $\mathrm{p}$-xylene $(\mathrm{m} / \mathrm{z}=106)$ integrated from their individual peak areas in the mass spectra decreased linearly with their diluted concentrations. As an example, a typical mass spectrum of the species with diluted concentrations of 22 ppbv, accumulated for $60 \mathrm{~s}$, is presented in Fig. 5(b) and displays a near zero baseline. The ion peaks of benzene, toluene and p-xylene with their individual ${ }^{13} \mathrm{C}$ isotopic species at $\mathrm{m} / \mathrm{z}=79,93$ and 107 are observed in the mass spectrum.
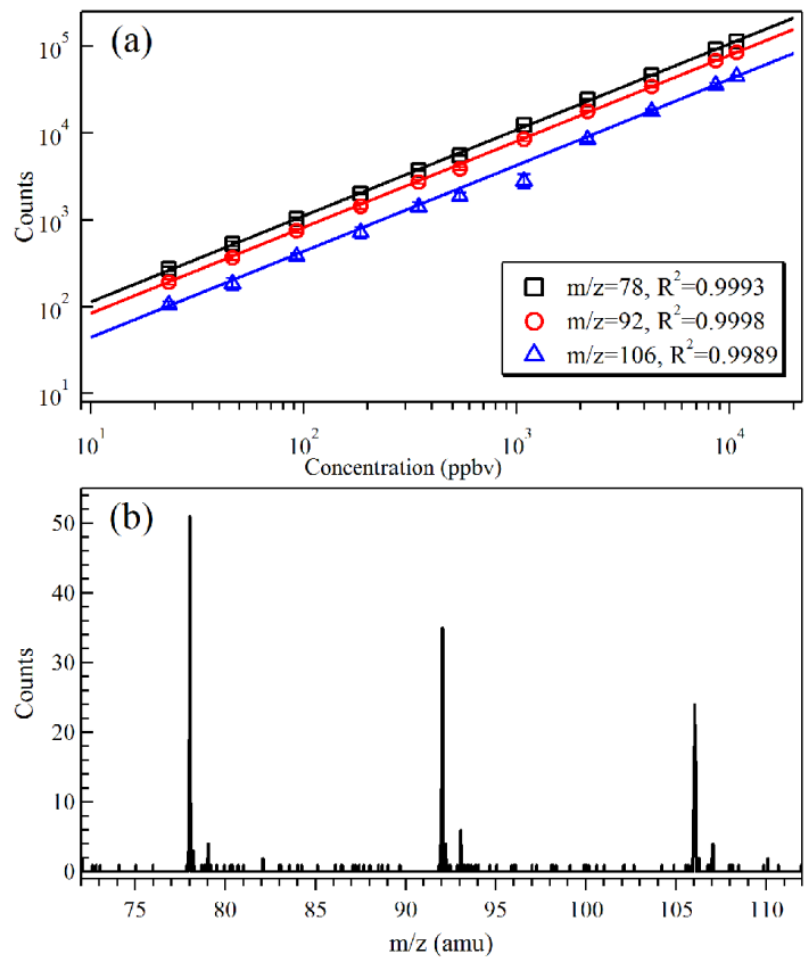

FIG. 5. (a) The ion intensities of benzene $(\mathrm{m} / \mathrm{z}=78)$, toluene $(\mathrm{m} / \mathrm{z}=92)$, and $\mathrm{p}$-xylene $(\mathrm{m} / \mathrm{z}=106)$ in photoionization mass spectra change linearly with their concentrations. (b) Photoionization mass spectrum of the mixture at a concentration of 22 ppbv acquired via the capillary effusive beam sampling.

The LOD of the VUVPI-TOFMS can be calculated with a signal-to-noise ratio of 3 from the photoionization mass spectrum via the equation $\mathrm{E} 1,32,33$ 


$$
\mathrm{LOD}=3 \sigma \mathrm{c} /(\mathrm{S}-\mathrm{B})
$$

where $\sigma$ is the amplitude variance of the signal between peaks, $\mathrm{C}$ is the species concentration, $\mathrm{S}$ is the peak height and $\mathrm{B}$ is the mean value of the noise. In the mass spectrum of Fig. 5(b), $\sigma$ takes the value of 0.18 between the peaks of $\mathrm{m} / \mathrm{z}=80$ and 90 , and $\mathrm{B}$ is calculated to be 0.03 . The ion peaks of benzene, toluene and p-xylene have the counts of 51, 35 and 24. Then the LODs of the VUVPI-TOFMS with the capillary sampling are calculated at 0.3, 0.4 and $0.5 \mathrm{ppbv}$ for benzene, toluene and p-xylene, respectively, with an accumulation time of $60 \mathrm{~s}$. As listed in Table 1, the LOD of this VUVPI-TOFMS is lower than those of the setups using synchrotron radiations, lasers and some lamps as photoionization light source. In addition, although the pressure inside the cage-shaped photoionization source is low at only $10^{-2} \mathrm{~Pa}$, this VUVPI-TOFMS benefits from the ion focusing electric field which makes its LOD comparable to the setups with medium pressure ionization sources. ${ }^{18}$

\section{LOD of radicals}

In comparison to stable species, radicals must be produced from reactions online and normally their concentrations are not known in advance. In photoionization mass spectra, the ion signal $I$ is proportional to the specie's concentration $N$ and its photoionization cross section $\sigma$, following the equation $\mathrm{E} 2$,

$$
\mathrm{I}=\mathrm{C} \sigma \mathrm{N} \mathrm{m}^{\beta(\mathrm{P}, \mathrm{T})}
$$

where $C$ is the instrument factor, $m$ is the ion mass and $\beta$ is the mass discrimination factor. ${ }^{23}$ But because the VUV lamp has multiple output photon energies and thus the photoionization cross sections are not known, it is difficult to quantify the absolute concentrations of radicals by using the VUV lamp photoionization with the equation E2.

As we suggested before, the radical concentration can be determined by measuring their time resolved concentration during the self-reaction in the fast flow tube, and a LOD of $\sim 3$ ppbv has been reported for the methyl radical $\left(\mathrm{CH}_{3}\right) \cdot{ }^{30}$ Very recently, to demonstrate the availability of the self-reaction method to measure the radical concentrations, we carried out synchrotron experiments at Hefei Light Source with the fast flow tube and the VUV photoionization mass spectrometer. Ethyl radicals $\left(\mathrm{C}_{2} \mathrm{H}_{5}\right)$ were produced through the reaction of fluorine atoms with ethane. The concentrations of 
ethyl radicals were measured at several fixed synchrotron photon energies with two different methods, the self-reaction method with the available self-reaction rate constant of $\mathrm{C}_{2} \mathrm{H}_{5}$ and the photoionization cross section method with the calibrated concentrations of NO gas, together with the available photoionization cross sections of $\mathrm{C}_{2} \mathrm{H}_{5}$ and NO. The concentrations of $\mathrm{C}_{2} \mathrm{H}_{5}$ measured with the two different methods agree well and their relative errors are within $10-15 \%$. This work will be the subject of a forthcoming paper.

Presently the methyl radical self-reaction has been chosen again to measure the LOD of the new VUVPI-TOFMS with the cage-shaped photoionization source. The methyl radicals were produced in the fast flow tube through the $\mathrm{H}$-abstraction reaction from methane by fluorine atoms, which were formed in the microwave discharge of $F_{2}$ diluted in helium. A typical VUV lamp photoionization mass spectrum was measured at a pressure of 2 Torr inside the fast flow tube and is presented in Fig. 6(a). The peak at m/z $=15$ is assigned as $\mathrm{CH}_{3}$ with its adiabatic ionization energy at $9.80 \mathrm{eV} \cdot{ }^{31,34}$ Without other reactant gases, $\mathrm{CH}_{3}$ mainly decreased through self-reaction in the flow tube which has already been investigated in detail before. ${ }^{35,36}$ The self-reaction of $\mathrm{CH}_{3}$ mainly produces the product $\mathrm{C}_{2} \mathrm{H}_{6}$ with its ionization energy located at $11.52 \mathrm{eV}$, above the photon energies of the VUV lamp, and so the molecule was not observed in the mass spectrum. ${ }^{31}$

$$
\mathrm{CH}_{3}+\mathrm{CH}_{3} \rightarrow \text { products }
$$



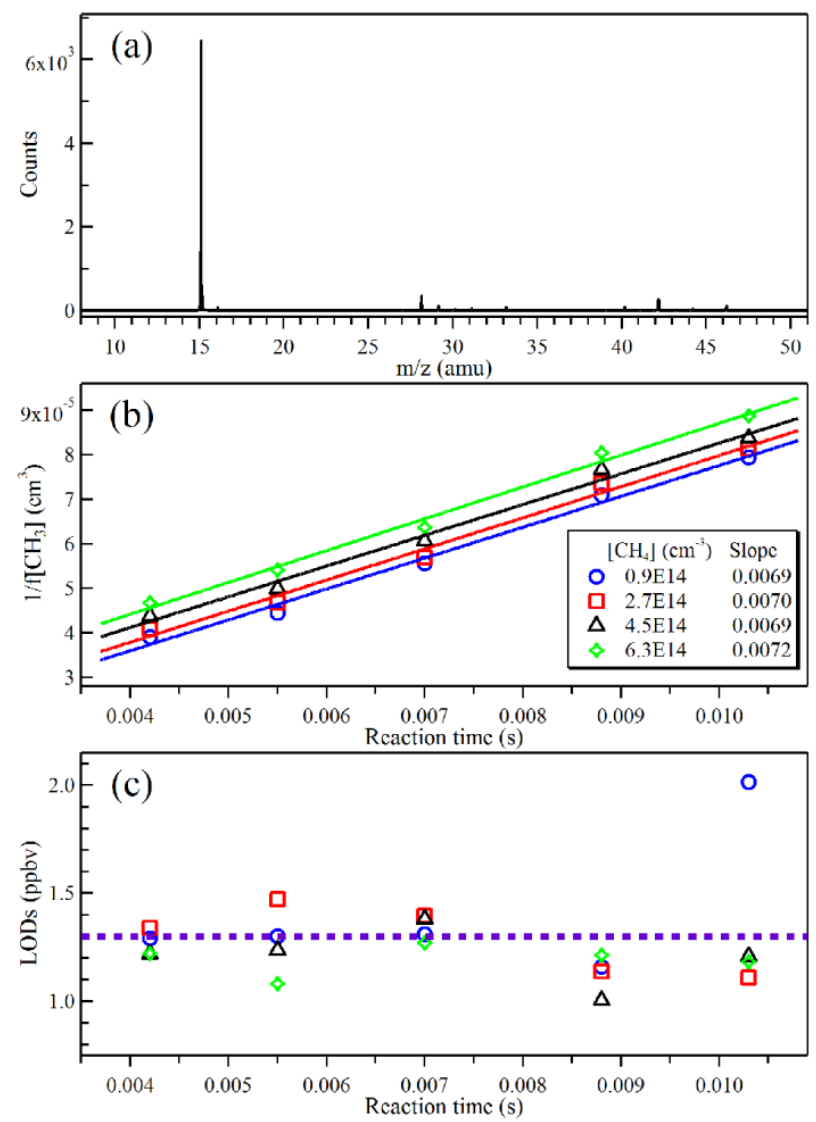

FIG. 6. (a) Photoionization mass spectrum of $\mathrm{CH}_{3}$. (b) The inverse intensity of $\mathrm{CH}_{3}$ in photoionization mass spectra changes linearly with reaction time in the self-reaction with different initial concentrations. (c) The LODs of $\mathrm{CH}_{3}$ determined from photoionization mass spectra (open symbols) and its average value marked with a purple dashed line.

Briefly, the self-reaction of $\mathrm{CH}_{3}$ is a second-order reaction and its inverse concentration $\left(1 /\left[\mathrm{CH}_{3}\right]\right)$ changes linearly with reaction time, $t$, following the equation $\mathrm{E} 4$,

$$
\frac{1}{\left[\mathrm{CH}_{3}\right]}=\frac{1}{\left[\mathrm{CH}_{3}\right]_{0}}+2 \mathrm{k} t
$$

where $\left[\mathrm{CH}_{3}\right]_{0}$ is the initial concentration of $\mathrm{CH}_{3}$ and $k$ is the rate constant at $5.52 \times 10^{-11}$ $\mathrm{cm}^{3}$ molecule $\mathrm{s}^{-1} \cdot 35,36$ As shown in Fig. 6(b), the inverse intensities of $\mathrm{CH}_{3}$ in the photoionization mass spectra with different initial concentrations of $\mathrm{CH}_{3}$ change linearly with reaction time and agree well with the kinetics of a second-order reaction, also demonstrating that methyl radicals majorly performed self-reaction in the flow tube.

As shown in the equation $\mathrm{E} 2$, the ion signals of $\mathrm{CH}_{3}$ in the photoionization mass spectra are proportional to their concentrations, $\mathrm{I}_{\mathrm{CH} 3} \propto \mathrm{f}\left[\mathrm{CH}_{3}\right]$, and the scaling factor, $f$, 
can be calibrated with the known rate constant ${ }^{35,36}$ and the slopes of the lines in Fig. 6(b) through the equation E4'.

$$
\frac{1}{f\left[\mathrm{CH}_{3}\right]}=\frac{1}{f\left[\mathrm{CH}_{3}\right]_{0}}+\frac{2 \mathrm{k}}{f} t
$$

The slopes of the lines $(2 \mathrm{k} / \mathrm{f})$ in Fig. 6(b) are fitted and take an average value of 0.007 counts $^{-1} \mathrm{~s}^{-1}$, and then the scaling factor is determined to be $\mathrm{f}=1.6 \times 10^{-8}$ counts $\mathrm{cm}^{3}$ molecule ${ }^{-1}$ with the self-reaction rate constant $\mathrm{k}$ at $5.52 \times 10^{-11} \mathrm{~cm}^{3}$ molecule $\mathrm{s}^{-1} .^{35,36}$. So the absolute concentration of $\mathrm{CH}_{3}$ at each reaction time with different initial concentrations are determined. For example, the concentration of $\mathrm{CH}_{3}$ in Fig. 6(a) is calculated to be $1.6 \times 10^{12}$ molecule $\mathrm{cm}^{-3}$ from the ratio of its intensity in the mass spectrum and the scaling factor. Then based on the equation E1, the $\mathrm{LODs}$ of $\mathrm{CH}_{3}$ are calculated from the photoionization mass spectra with different conditions and shown in Fig. 6(c). The LOD of $\mathrm{CH}_{3}$ takes an average value of $1.3 \pm 0.2 \mathrm{ppbv}$, which is 2.3 times lower than our previous result of 3 ppbv, ${ }^{30}$ benefiting of the ion focusing electric field and in good agreement with the improvement presented in the Section III. A.

\section{Initial applications of VUVPI-TOFMS: The chlorine-initiated oxidation of toluene}

As representative examples, the chlorine initiated oxidation of toluene has been investigated in the atmospheric simulation chamber at atmospheric pressure and in the fast flow tube at 2 Torr.

In the simulation chamber, Cl-atoms were generated through the UV photolysis of 5 ppmv (parts per million by volume) trichloroacetyl chloride $\left(\mathrm{CCl}_{3} \mathrm{CClO}\right) .{ }^{37}$ Clean air was added as bath gas and the initial concentration of toluene was $1.5 \mathrm{ppmv}$.

The photoionization mass spectra with the UV lamps off and on were measured and are presented in Fig. 7(a) and (b), respectively. An intense mass peak at $\mathrm{m} / \mathrm{z}=92$ is observed and assigned as toluene $\left(\mathrm{C}_{7} \mathrm{H}_{8}\right)$. The peak at $\mathrm{m} / \mathrm{z}=93$ takes an intensity of $\sim 0.1$ of the $\mathrm{m} / \mathrm{z}=92$ peak and is ascribed to the ${ }^{13} \mathrm{C}$-toluene isotope. The ionization energy of $\mathrm{CCl}_{3} \mathrm{CClO}$ is at $11.3 \mathrm{eV}$, above the photon energies of the VUV lamp, and the species was thus not observed in the mass spectra. ${ }^{31}$ After turning on the UV lamps, Cl-atoms were produced and the oxidation reaction of toluene was initiated. The build-up of 
several other peaks besides toluene is then observed in the mass spectrum, as shown in Fig. 7(b). These peaks are assigned to the oxidation products glyoxal $\left(\mathrm{C}_{2} \mathrm{H}_{2} \mathrm{O}_{2}, \mathrm{~m} / \mathrm{z}=58\right)$, methyl glyoxal $\left(\mathrm{C}_{3} \mathrm{H}_{4} \mathrm{O}_{2}, \mathrm{~m} / \mathrm{z}=72\right)$, benzene $\left(\mathrm{C}_{6} \mathrm{H}_{6}, \mathrm{~m} / \mathrm{z}=78\right)$ and benzaldehyde $\left(\mathrm{C}_{7} \mathrm{H}_{6} \mathrm{O}\right.$, $\mathrm{m} / \mathrm{z}=106) .{ }^{38,39}$ Benzyl alcohol $\left(\mathrm{C}_{7} \mathrm{H}_{8} \mathrm{O}, \mathrm{m} / \mathrm{z}=108\right)$ is at the most a very minor product, in contrast to the findings of Nozière et al. ${ }^{40}$ However, due to the capillary sampling, the reactive intermediates involved in the oxidation process were not transferred into the VUVPI-TOFMS and have thus not been detected.
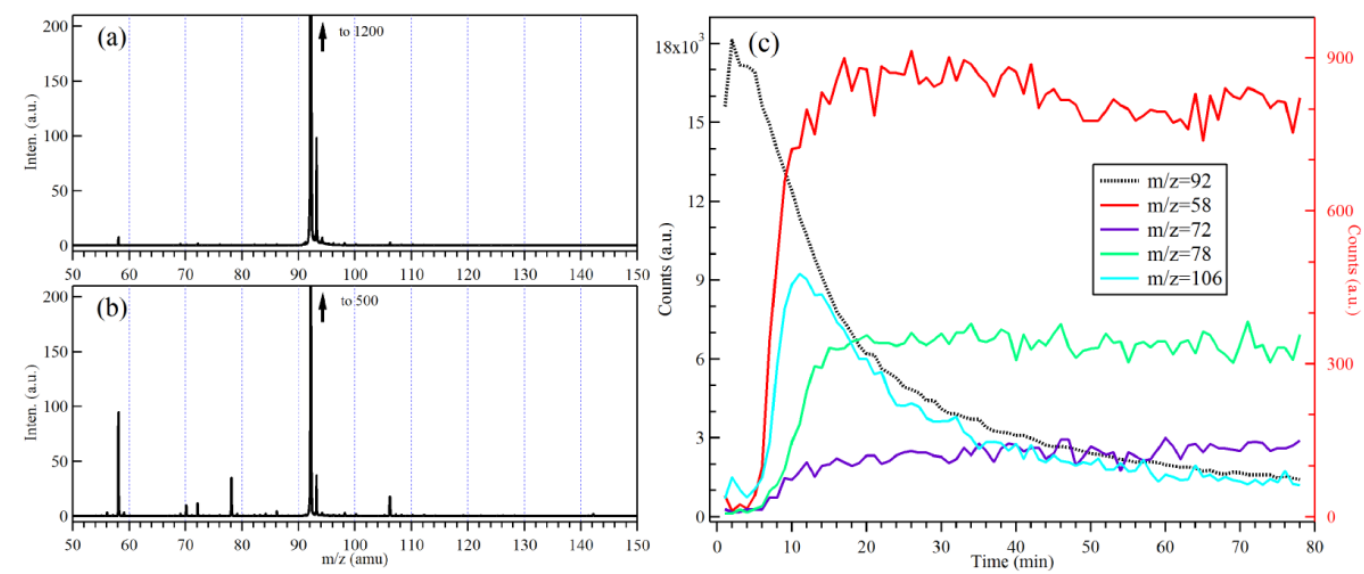

FIG. 7. Photoionization mass spectra of the chlorine-initiated oxidation of toluene with the UV lamps (a) off and (b) on since at $\sim 4 \mathrm{~min}$ in the atmospheric simulation chamber. (c) The ion intensity of the products changes with time, where the left axis shows the scale of toluene $(\mathrm{m} / \mathrm{z}=$ 92) and the right axis presents the scales of the reaction products (color lines).

Fig. 7(c) presents the change of the ion intensities of toluene and of the oxidation products as a function of the reaction time in the atmospheric simulation chamber, with a time resolution of $1 \mathrm{~min}$. We can see that after turning on the UV lamps (at $\sim 4 \mathrm{~min}$ ), the ion intensity of toluene (in black, left y-axis) decreased and the ion intensity of the products increased within several minutes. For benzaldehyde (in cyan, $\mathrm{m} / \mathrm{z}=106$, right $\mathrm{y}$ axis), the signal increased to the maximum at 11 minutes and then decreased. This can be explained by the fact that (i) the production of benzaldehyde is exclusively due to the $\mathrm{Cl}+$ toluene reaction and thus, as toluene decreases, its production decreases as well; and (ii) the secondary reaction of $\mathrm{Cl}+$ benzaldehyde is faster $\left(\mathrm{k}=8.9 \times 10^{-11} \mathrm{~cm}^{3}\right.$ molecule ${ }^{-1} \mathrm{~s}^{-}$ $\left.{ }^{1}\right)^{41}$ than the $\mathrm{Cl}+$ toluene reaction $\left(\mathrm{k}=5.8 \times 10^{-11} \mathrm{~cm}^{3} \text { molecule }{ }^{-1} \mathrm{~s}^{-1}\right)^{42}$, and thus with increasing benzaldehyde and decreasing toluene concentrations the $\mathrm{Cl}$-atoms react increasingly with benzaldehyde rather than with toluene. As the photoionization cross section of benzaldehyde is almost the same as that of toluene at $\mathrm{hv}=10.6 \mathrm{eV},{ }^{43}$ the 
benzaldehyde concentration at 11 minutes was calculated to be about 50 ppbv based on the calibrated concentration of toluene in the photoionization mass spectra.

For the products glyoxal $(\mathrm{m} / \mathrm{z}=58)$, methyl glyoxal $(\mathrm{m} / \mathrm{z}=72)$ and benzene $(\mathrm{m} / \mathrm{z}=$ 78), their intensities increased with the reaction time and approached a steady-state after $\sim 15$ minutes, meaning that the production rate of these species is roughly as fast as their consumption. This is a very brief analysis and the inherent mechanism in the atmospheric simulation chamber needs to be simulated to get a more detailed answer, ${ }^{44,45}$ which is out of the scope of this manuscript.

The chlorine-initiated oxidation of toluene was also studied in the fast flow tube at 2 Torr. Chlorine atoms were generated by the microwave discharge of $1 \% \mathrm{Cl}_{2}$ diluted in helium and fed into the fast flow tube via the injector. Toluene was added by bubbling helium through a reservoir with liquid toluene, and oxygen gas was added through a calibrated mass flow meter, both were introduced into the main tube through side arms.
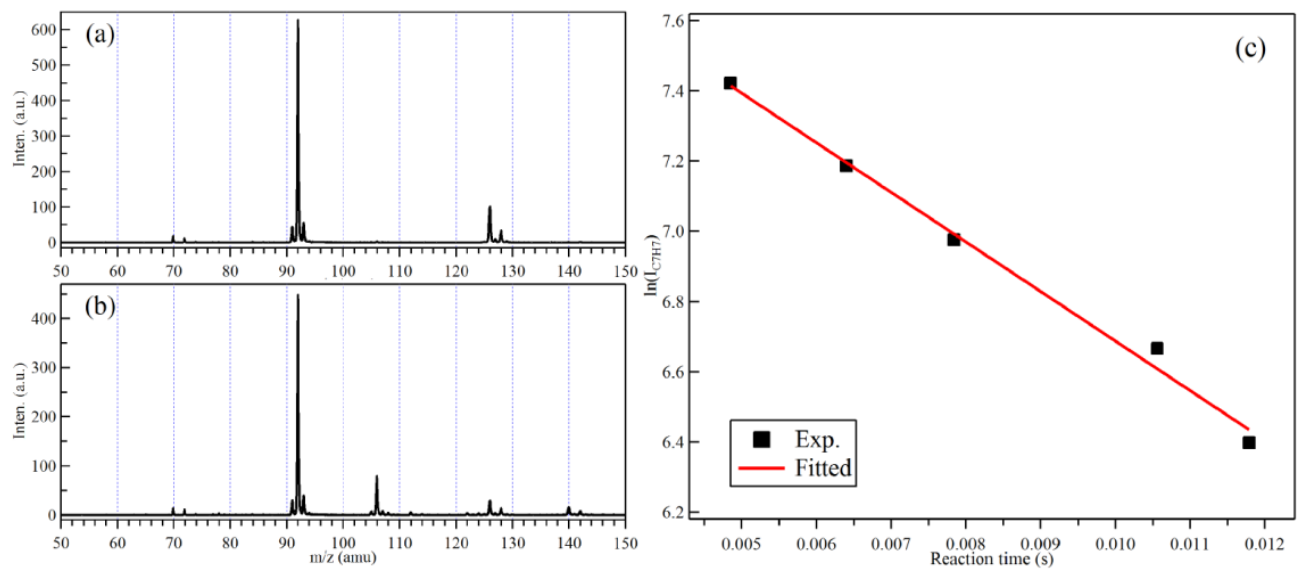

FIG. 8. Photoionization mass spectra of the chlorine-initiated oxidation of toluene (a) without and (b) with adding oxygen gas in fast flow tube. (c) Plot of the logarithmic ion intensity of the benzyl radical versus reaction time, with the initial oxygen concentration of $\left[\mathrm{O}_{2}\right]=8.7 \times 10^{13} \mathrm{~cm}^{-3}$.

Photoionization mass spectra were obtained without and with adding oxygen in the fast flow tube and are presented in Fig. 8(a) and (b). Similar to the above chamber experiments, the most intense ion peak in the photoionization mass spectra is at $\mathrm{m} / \mathrm{z}=92$ and is attributed to toluene, together with its ${ }^{13} \mathrm{C}$-toluene isotope at $\mathrm{m} / \mathrm{z}=93$. But in this setup with the molecular beam sampling, the reaction intermediate benzyl radical $\left(\mathrm{C}_{7} \mathrm{H}_{7}\right)$, obtained from the $\mathrm{H}$-abstraction reaction of toluene with chlorine atom, was also detected and can be clearly identified at $\mathrm{m} / \mathrm{z}=91$ in the photoionization mass spectra. In addition, 
two other peaks at $\mathrm{m} / \mathrm{z}=126$ and 128 can be observed in the mass spectra too and are assigned as $\mathrm{C}_{7} \mathrm{H}_{7}{ }^{35} \mathrm{Cl}$ and $\mathrm{C}_{7} \mathrm{H}_{7}{ }^{37} \mathrm{Cl}$, the products of the secondary reaction of the benzyl radical with chlorine atoms, or with remaining $\mathrm{Cl}_{2}$. ${ }^{46,47}$ The ratio of the $\mathrm{C}_{7} \mathrm{H}_{7}{ }^{35} \mathrm{Cl}$ and $\mathrm{C}_{7} \mathrm{H}_{7}{ }^{37} \mathrm{Cl}$ peaks is about 3:1, agreeing well with the natural abundances of ${ }^{35} \mathrm{Cl}$ and ${ }^{37} \mathrm{Cl}$ isotopes.

After addition of excess oxygen relative to benzyl radicals and chlorine atoms into the flow tube, the peak at $\mathrm{m} / \mathrm{z}=106$ appeared in the photoionization mass spectrum of Fig. 8(b) and is assigned as benzaldehyde $\left(\mathrm{C}_{7} \mathrm{H}_{6} \mathrm{O}\right)$ from the oxidation reaction of the benzyl radical, and at the same time the ion intensities of the secondary reaction products $\mathrm{C}_{7} \mathrm{H}_{7}{ }^{35} \mathrm{Cl}$ and $\mathrm{C}_{7} \mathrm{H}_{7}{ }^{37} \mathrm{Cl}$ decreased. Fig. 8(c) presents the ion intensity of the benzyl radical versus reaction time, obtained through changing the distance between the tip of the injector and the detection region. A good linearity can be found for the decrease of the logarithmic ion intensity of the benzyl radical as a function of the reaction time, in agreement with a pseudo-first-order reaction kinetics. The obtained pseudo-first order rate constant is $142 \mathrm{~s}^{-1}$, which would result in a rate constant of $\mathrm{k}_{\mathrm{C} 7 \mathrm{H} 7+\mathrm{O} 2}=1.6 \times 10^{-12}$ $\mathrm{cm}^{3}$ molecule $\mathrm{s}^{-1}$, in accordance with the result of Nelson and McDonald $\left(1.5 \times 10^{-12}\right.$ $\mathrm{cm}^{3}$ molecule $\left.{ }^{-1} \mathrm{~s}^{-1}\right),{ }^{47}$ but higher than the literature data of Bartels et al $\left(4.98 \times 10^{-13}\right.$ $\mathrm{cm}^{3}$ molecule $\left.\mathrm{s}^{-1}\right)^{42}$. In our case, neglecting the loss of benzyl radicals through selfreaction, wall and reaction with remaining $\mathrm{Cl}_{2}$ will lead to somewhat overestimation of the rate constant and can explain the difference.

\section{CONCLUSIONS}

A VUV photoionization orthogonal acceleration reflectron time-of-flight mass spectrometer (VUVPI-TOFMS) based on a commercial $10.6 \mathrm{eV}$ krypton lamp has been developed to study gas-phase radical reactions. An atmospheric simulation chamber operated at atmospheric pressure and a fast flow tube operated at low pressure (1-10 Torr) are employed as chemical reactors to initiate radical reactions of atmospheric interest at different pressures and allowing studying the time-resolved evolution of the gas mixture over different reaction times, in the minutes to hours range in the atmospheric simulation chamber and in the milliseconds range in the fast flow tube. The atmospheric simulation chamber and the flow tube are connected to the VUVPI-TOFMS for online product 
analysis via a capillary effusive beam and a continuous molecular beam, respectively, which can be operated independently and switched conveniently in-between within minutes.

Several strategies like installing the krypton lamp just above the photoionization region within vacuum and utilizing dual pulses to reduce background signals have been employed in the VUVPI-TOFMS to enhance its detection sensitivity. In particular, a cage-shaped photoionization source has been designed leading to an ion focusing electric field to allow all the ions formed along the long light path of the krypton lamp to be extracted and collected. Thus the novel configuration of the photoionization source could compensate the low photon flux of the krypton lamp and provide a high detection efficiency. Some preliminary experiments have been performed including the selfreaction of methyl radicals and the chlorine-initiated oxidation of toluene in the fast flow tube or the atmospheric simulation chamber. The present experimental results have demonstrated that both stable species and reactive intermediates can be detected with a high sensitivity: the achieved LODs are down to the sub-ppbv concentration range, e.g. $0.3 \mathrm{ppbv}$ for benzene and $1.3 \mathrm{ppbv}$ for the methyl radical, without any pretreatments, providing a great potential to reveal the complex chemical mechanism of atmospherically relevant radical reactions in detail.

\section{ACKNOWLEDGEMENTS}

This work was financially supported by the National Natural Science Foundation of China (NSFC, Nos. 21773249, 91961123, 91644109), the National Key R\&D Program of China (NO. 2016YFC0200300) and the International Partnership Program of Chinese Academy of Sciences (No. 116134KYSB20170048). C.F. would like to thank the support of the Chinese Academy of Sciences President's International Fellowship Initiative (PIFI, No. 2018VMA0055) and the Xu Guangqi program (No. 43270ZD).

\section{REFERENCES}

${ }^{1}$ J. H. Gross, Mass spectrometry. (Springer Berlin Heidelberg, 2011).

${ }^{2}$ R. Jirasko and M. Holcapek, Mass Spectrom. Rev. 30, 1013 (2011).

${ }^{3}$ C. Y. Ng, Annu. Rev. Phys. Chem. 53, 101 (2002). 
${ }^{4}$ J. D. Savee, E. Papajak, B. Rotavera, H. Huang, A. J. Eskola, O. Welz, L. Sheps, C. A. Taatjes, J. Zádor and D. L. Osborn, Science 347, 643 (2015).

${ }^{5}$ F. Qi, P. Combust. Inst. 34, 33 (2013).

${ }^{6}$ X. Tang, G. A. Garcia, J.-F. Gil and L. Nahon, Rev. Sci. Instrum. 86, 123108 (2015).

${ }^{7}$ D. L. Osborn, P. Zou, H. Johnsen, C. C. Hayden, C. A. Taatjes, V. D. Knyazev, S. W. North, D. S. Peterka, M. Ahmed and S. R. Leone, Rev. Sci. Instrum. 79, 104103 (2008).

${ }^{8}$ Z. Zhou, X. Du, J. Yang, Y. Wang, C. Li, S. Wei, L. Du, Y. Li, F. Qi and Q. Wang, J. Synchrotron Rad. 23, 1035 (2016).

${ }^{9}$ X. Tang, G. A. Garcia and L. Nahon, J. Chem. Phys. 148, 124309 (2018).

${ }^{10}$ H. Zacharias, H. Rottke and K. H. Welge, Opt. Commun. 35, 185 (1980).

${ }^{11}$ P. Chen, S. D. Colson and W. A. Chupka, Chem. Phys. Lett. 147, 466 (1988).

${ }^{12}$ J. W. Hepburn, Isr. J. Chem. 24, 273 (1984).

${ }^{13}$ T. M. Lenhardt, C. E. McDade and K. D. Bayes, J. Chem. Phys. 72, 304 (1980).

${ }^{14}$ I. R. Slagle and D. Gutman, J. Am. Chem. Soc. 107, 5342 (1985).

${ }^{15}$ C. Fockenberg, H. J. Bernstein, G. E. Hall, J. T. Muckerman, J. M. Preses, T. J. Sears and R. E. Weston Jr, Rev. Sci. Instrum. 70, 3259 (1999).

${ }^{16}$ K. Tonokura, N. Kanno, Y. Yamamoto and H. Yamada, Int. J. Mass spectrom. 290, 9 (2010).

17 J. E. Middaugh, Z. J. Buras, M. Matrat, T.-C. Chu, Y.-S. Kim, I. M. Alecu, A. K. Vasiliou, C. F. Goldsmith and W. H. Green, Rev. Sci. Instrum. 89, 074102 (2018).

${ }^{18}$ L. Hua, Q. Wu, K. Hou, H. Cui, P. Chen, W. Wang, J. Li and H. Li, Anal. Chem. 83, 5309 (2011).

${ }^{19}$ Y. Wang, J. Jiang, L. Hua, K. Hou, Y. Xie, P. Chen, W. Liu, Q. Li, S. Wang and H. Li, Anal. Chem. 88, 9047 (2016).

${ }^{20}$ F. Mühlberger, T. Streibel, J. Wieser, A. Ulrich and R. Zimmermann, Anal. Chem. 77, 7408 (2005).

${ }^{21}$ W. Sun, J. Shu, P. Zhang, Z. Li, N. Li, M. Liang and B. Yang, Atmos. Meas. Tech. 8, 4637 (2015).

${ }^{22}$ H. Xu and S. T. Pratt, J. Phys. Chem. A 117, 9331 (2013).

${ }^{23}$ T. A. Cool, J. Wang, K. Nakajima, C. A. Taatjes and A. McIlroy, Int. J. Mass spectrom. 247, 18 (2005).

${ }^{24}$ L. G. Dodson, J. D. Savee, S. Gozem, L. Shen, A. I. Krylov, C. A. Taatjes, D. L. Osborn and M. Okumura, J. Chem. Phys. 148 (2018).

${ }^{25}$ B. Gans, G. A. Garcia, S. Boye-Peronne, J.-C. Loison, S. Douin, F. Gaie-Levrel and D. Gauyacq, J. Phys. Chem. A 115, 5387 (2011).

${ }^{26}$ X. Tang, X. Zhou, M. Niu, S. Liu, J. Sun, X. Shan, F. Liu and L. Sheng, Rev. Sci. Instrum. 80, 113101 (2009).

${ }^{27}$ Y. Gai, X. Lin, Q. Ma, C. Hu, X. Gu, W. Zhao, B. Fang, W. Zhang, B. Long and Z. Long, Environ. Sci. Technol. 49, 10380 (2015).

${ }^{28}$ G. Pan, C. Hu, Z. Wang, Y. Cheng, X. Zheng, X. Gu, W. Zhao, W. Zhang, J. Chen, F. Liu, X. Shan and L. Sheng, Rapid Commun. Mass Spectrom. 26, 189 (2012).

${ }^{29}$ G. A. Garcia, X. Tang, J.-F. Gil, L. Nahon, M. Ward, S. Batut, C. Fittschen, C. A. Taatjes, D. L. Osborn and J.-C. Loison, J. Chem. Phys. 142 (2015).

${ }^{30}$ Z. Wen, X. Tang, C. Wang, C. Fittschen, T. Wang, C. Zhang, J. Yang, Y. Pan, F. Liu and W. Zhang, Int. J. Chem. Kinet. 51, 178 (2019). 
${ }^{31}$ NIST Chemistry WebBook, http://webbook.nist.gov/chemistry/, (Retrieved on October 1, 2019)

${ }^{32}$ B. A. Williams, T. N. Tanada and T. A. Cool, in Twenty-Fourth Symposium (International) on Combustion (Pittsburgh, PA: The Combustion Institute, 1992), pp. 1587.

${ }^{33}$ H. J. Heger, R. Zimmermann, R. Dorfner, M. Beckmann, H. Griebel, A. Kettrup and U. Boesl, Anal. Chem. 71, 46 (1999).

${ }^{34}$ Y. Zhu, X. Wu, X. Tang, Z. Wen, F. Liu, X. Zhou and W. Zhang, Chem. Phys. Lett. 664, 237 (2016).

${ }^{35}$ B. Wang, H. Hou, L. M. Yoder, J. T. Muckerman and C. Fockenberg, J. Phys. Chem. A 107, 11414 (2003).

${ }^{36}$ V. Riffault, Y. Bedjanian and G. Le Bras, J. Phys. Chem. A 107, 5404 (2003).

${ }^{37}$ B. J. Finlayson-Pitts, C. J. Keoshian, B. Buehler and A. A. Ezell, Int. J. Chem. Kinet. 31, 491 (1999).

${ }^{38}$ S. V. Dhulipala, S. Bhandari and L. H. Ruiz, Atmos. Environ. 199, 265 (2019).

${ }^{39}$ P. S. Chhabra, N. L. Ng, M. R. Canagaratna, A. L. Corrigan, L. M. Russell, D. R. Worsnop, R. C. Flagan and J. H. Seinfeld, Atmos. Chem. Phys. 11, 8827 (2011).

${ }^{40}$ B. Noziere, R. Lesclaux, M. D. Hurley, M. A. Dearth and T. J. Wallington, J. Phys. Chem. 98, 2864 (1994).

${ }^{41}$ R. Buth, K. Hoyermann and G. Rohde, Symp. Int. Combust. Proc. 24, 669 (1992).

${ }^{42}$ M. Bartels, J. Edelbuttel-Einhaus and K. Hoyermann, Symp. Int. Combust. Proc. 22, 1041 (1989).

${ }^{43}$ Z. Zhou, M. Xie, Z. Wang and F. Qi, Rapid Commun. Mass Spectrom. 23, 3994 (2009).

${ }^{44}$ R. L. Caravan, M. A. H. Khan, J. Zador, L. Sheps, I. O. Antonov, B. Rotavera, K. Ramasesha, K. Au, M.-W. Chen, D. Rosch, D. L. Osborn, C. Fittschen, C. Schoemaecker, M. Duncianu, A. Grira, S. Dusanter, A. Tomas, C. J. Percival, D. E. Shallcross and C. A. Taatjes, Nat. Commun. 9, 434 (2018).

${ }^{45}$ G. Fantechi, N. R. Jensen, O. Saastad, J. Hjorth and J. Peeters, J. Atoms. Chem. 31, 247 (1998).

${ }^{46}$ F. Markert and P. Pagsberg, Chem. Phys. Lett. 209, 445 (1993).

${ }^{47}$ H. H. Nelson and J. R. McDonald, J. Phys. Chem. 86, 1242 (1982). 